\title{
A LINGUAGEM DAS RESISTÊNCIAS: CONSIDERAÇÕES SOBRE $O$ TRAUMA NA CLÍNICA PSICANALÍTICA
}

Fernanda Canavêz e Regina Herzog

Fernanda Canavêz

Psicanalista, doutora em Teoria Psicanalítica pela Universidade Federal do Rio de Janeiro (PPGTP/ UFRJ).

Regina Herzog

Psicanalista, professora associada do Programa de Pós-Graduação em Teoria Psicanalítica (PPGT/UFRJ).

Bolsista de produtividade em pesquisa do CNPq.
RESUMO: Pretende-se discutir a insistência da dimensão traumática na clínica psicanalítica contemporânea à luz do tema da linguagem. Isso porque as narrativas decorrentes de um choque traumático mostram-se predominantemente marcadas pela literalidade, constituídas por palavras intensas e apartadas das cadeias de representações. Trata-se de um recurso distinto da construção metafórica, que caracterizava os relatos nas neuroses clássicas, modalidades de padecimento psíquico que preconizaram a técnica interpretativa à época do surgimento da psicanálise. Sugere-se que tais narrativas evidenciam uma linguagem das resistências, convocando o analista a extrapolar a atitude de suspeita corrente na técnica interpretativa no intuito de instaurar a confiança.

Palavras-chave: Trauma, resistência, linguagem, interpretação, clínica psicanalítica.

ABSTRACT: Resistances' language: considerations about trauma in psychoanalytic clinics. It is intended to discuss the persistence of traumatic dimension in contemporary psychoanalytic clinics in the light of the theme of language. Narratives resulting from a traumatic shock are predominantly marked by literalness, consisting of intense words and splited by chains of representations. It is a distinct feature of metaphorical construction that characterized the classical neuroses, psychic modalities of suffering that advocated interpretative technique at the time of the emergence of psychoanalysis. It is suggested that these narratives enlighten resistances' language, calling the analyst to extrapolate the current attitude of suspicion in the interpretative technique in order to build confidence.

Keywords: Trauma, resistance, language, interpretation, psychoanalytic clinics. 


\section{INTRODUÇÃO}

A clínica psicanalítica atual enfrenta desafios de diferentes ordens, seja pela exigência de reafirmação frente às críticas que lhe são endereçadas ou pela própria necessidade de reinventar o dispositivo clínico aventado por Freud devido às peculiaridades do mal-estar contemporâneo em relação àquele de sua época. As críticas não constituem novidade, outrora interpretadas por Freud (1925[1924]/1990) como fonte de resistência que deveria ser neutralizada, embora se mostrem cada vez mais ácidas graças ao imperativo de um determinado modelo de cura fomentado na sociedade atual, calcado, sobretudo, no incremento do processo de medicalização do social.

Tal imperativo coloca em xeque a eficácia terapêutica da clínica psicanalítica, bem como a pertinência de sua utilização em um contexto marcadamente distinto da sociedade moderna, ocasião do surgimento da psicanálise. Há inúmeros exemplos desse tipo de discurso, desde produções jornalísticas a artigos acadêmicos. Talvez o caso mais paradigmático dos últimos anos seja $\mathrm{O}$ livro negro da psicanálise (2005), responsável por aquecer o referido debate.

Com efeito, o assunto das modalidades de mal-estar contemporâneas é amplamente encontrado na literatura psicanalítica, em que pese a insistência da dimensão traumática naquelas, a qual salienta a recalcitrância ao dispositivo terapêutico clássico. A suposição de uma maior suscetibilidade ao trauma na contemporaneidade tem sido indicada por diversos autores do campo, como sugerem Herzog (2010) e Birman (2003), intimamente associada às hipóteses da pregnância do tempo eminentemente presentificado na economia subjetiva, bem como da dificuldade de elaboração psíquica com a qual os neuróticos modernos contavam.

O que está em questão, em última instância, é a possibilidade de representar o trauma, suspeita inaugurada devido às mudanças operadas na modernidade, embora exponha toda a sua contundência na clínica psicanalítica atual, marcada que é pela chamada economia do trauma. A afirmação de uma "predisposição" ao trauma encontra-se formalizada no pensamento de Freud (1920/1992) com a indicação de um além do princípio do prazer, mas supomos que, antes mesmo disso, a própria emergência da psicanálise enquanto método de tratamento se coaduna com a necessidade de repensar a narrativa tradicional face à realidade do trauma, tal como se apresentava à época.

Esta constituiu uma das questões mais prementes para a sociedade moderna, como exemplificam as teses de Walter Benjamin sobre o declínio da experiência e da narrativa a ela relacionada: a maneira de narrar corrente até então teria sido esfacelada na modernidade devido à perda da experiência compartilhada (BENJAMIN, 1932/2000), preconizando um modo de narrativa capaz de contemplar as fissuras inerentes aos traumas colecionados na ocasião (BENJAMIN, 1936/2000), 
entre os quais é possível elencar os efeitos da Primeira Guerra Mundial como paradigmáticos.

Portanto, a psicanálise figura, de saída, como uma via marginal em relação à narrativa tradicional que busca incluir os efeitos do trauma na tarefa de construir uma história. Essa tarefa, todavia, insiste em se colocar na contemporaneidade, embora agora contemos com outros coloridos, os traumas característicos de nossa época, que reafirmam a necessidade de problematizar a linguagem utilizada na experiência analítica.

No intuito de discutir o estatuto da linguagem na experiência analítica atual e, sobretudo, da resistência em tal contexto, partimos da hipótese de uma verdadeira subversão operada pelo pensamento freudiano no que diz respeito à lógica dicotômica tão corrente à época moderna. É possível encontrar ressonâncias desta em pares como representação/irrepresentável, corpo/psiquismo, linguagem/coisa, afeto/linguagem, dentre outros dos quais não escapou o discurso freudiano, marcado que foi pelo imaginário de sua época. Entretanto, suspeitamos que a leitura de Freud da qual lançamos mão no presente artigo permite ultrapassar essas dicotomias, sugerindo um tipo de elaboração que extrapola o campo da representação e da linguagem em suas acepções formalistas. Destarte, estamos propondo que a linguagem seja pensada para além de sua versão formalista, marcada predominantemente por construções metafóricas, apontando para a dimensão afetiva na elaboração das resistências acirradas pela insistência do trauma.

Para dar conta desta proposta, faz-se premente discutir a resistência na obra freudiana, especialmente em seus pontos de toque com o conceito freudiano de elaboração. A relação entre resistência e elaboração leva-nos ainda à discussão do trauma, tendo em vista a indagação inicial sobre o estatuto da linguagem na clínica psicanalítica atual através de uma suscetibilidade traumática que demandaria reformulações teórico-clínicas. O pensamento freudiano será utilizado como fio norteador deste trabalho, muito embora as ideias de Sándor Ferenczi sejam incluídas em nosso arcabouço clínico-conceitual devido às inovações técnicas que propôs frente às resistências e às vicissitudes do trauma. Vale ainda mencionar a teoria benjaminiana sobre a linguagem e, em especial, sobre a tarefa do tradutor, das quais podem ser depreendidas importantes indicações no tocante à convocação feita ao analista por ocasião das narrativas decorrentes de experiências traumáticas.

\section{A ELABORAÇÃO DAS RESISTÊNCIAS}

A tarefa de discutir a elaboração das resistências na clínica psicanalítica impõe aquela preliminar de se debruçar sobre a metapsicologia da resistência construída 
por Freud. Essas formulações teóricas passaram por transformações que integram um conjunto maior de mudanças incluídas na técnica psicanalítica devido a impasses colecionados na clínica. Estas se dão a notar na interlocução de Freud com integrantes da chamada primeira geração de analistas, dentre os quais Ferenczi, cujo pensamento será privilegiado, conforme antevisto, devido ao tratamento especial concedido ao fenômeno da resistência na clínica por ele proposta.

O conceito de resistência, vale reiterar, não passou incólume pelas reviravoltas teórico-clínicas sofridas no desenrolar das formulações freudianas, de modo que sua abordagem metapsicológica — ou seja, realizada nas vertentes tópica, dinâmica e econômica do psiquismo - deve levar em consideração os cortes epistemológicos daquele. Na ocasião da estruturação da psicanálise como método de tratamento, a arte de clinicar nada mais era do que enfrentar os aguilhões da resistência evidenciados pelos quadros de histeria, estes recalcitrantes ao aparato neurológico até então em voga.

Tratava-se da exigência de superar as formas de resistência sob a égide do eu, quais sejam: a que concorre para a manutenção dos conteúdos ocultados pelo recalque, a proveniente do ganho secundário da enfermidade neurótica que concede ao eu benefícios e, finalmente, a decorrente do vínculo transferencial estabelecido com o analista, o qual, embora viabilize a confiança indispensável ao tratamento, não deixa de se erigir enquanto obstáculo devido à compulsão para repetir de que se faz partidário.

O quadro da primeira teoria pulsional freudiana é marcado pelo imperativo da modificação tópica em relação à resistência, na medida em que seria dissolvida ao se tornar consciente por intermédio da interpretação feita pelo analista. Trata-se de uma dimensão da elaboração que podemos considerar, a título de esclarecimento, de eminentemente cognitivista. A tentativa de elucidação, entretanto, não tardou a colecionar tropeços por diferentes motivos. A promessa de remissão sintomática não parecia suficiente para que os neuróticos, aferrados ao benefício secundário de suas enfermidades, colaborassem com o método de tornar consciente o inconsciente. Ademais, a repetição atuada na transferência escapava à possibilidade de elaboração circunscrita à modificação tópica, além de lançar luz sobre a implicação do próprio analista no tratamento, cuja postura neutra cai por terra com a elucidação acerca da contratransferência.

Por fim, vale ainda indicar que o tipo de pacientes que buscavam a psicanálise extrapolou aquele das histerias, por ocasião do qual Freud estruturara seu método. O caso do russo Sergei Pankejeff, popularizado como Homem dos lobos, é paradigmático no que diz respeito à modificação do perfil diagnóstico (FREUD, 1918[1914]/1990). Suas resistências, notadamente mais acirradas do que as das histéricas até então acompanhadas por Freud, fizeram com que este propusesse 
modificações técnicas, como o controverso estabelecimento de um prazo para o término do tratamento.

A interrupção desse tratamento coincide com a conceituação da elaboração (FREUD, 1914/1992), agora já circunscrita ao quadro de impasses que levaram à formalização posterior da pulsão de morte (FREUD, 1920/1992), cenário em que as vertentes dinâmica e econômica do psiquismo tornam-se pregnantes. A análise das resistências pautada pela modificação tópica não se mostrava mais suficiente frente às modalidades subjetivas perpassadas pela dimensão traumática que se furtava à interpretação. Era preciso pensar em um manejo clínico capaz de incluir as formas de mal-estar que resistiam ao dispositivo do qual a psicanálise dispunha à época, talvez o primeiro momento que exigiu reformulações da técnica analítica, como o que enfrentamos na contemporaneidade.

Kupermann (2010) indica que a elaboração surge como sintoma de um desafio clínico imposto a Freud, pois o método calcado na associação livre, no princípio da abstinência e na interpretação deixava a desejar frente a sujeitos comprometidos em sua capacidade de tornar consciente o inconsciente. $\mathrm{O}$ autor sugere o debate sobre a elaboração como um divisor de águas responsável por enaltecer as dimensões afetiva e estética da clínica, as quais devem ser privilegiadas se o que está em pauta é a discussão da elaboração que extrapola a linguagem e a representação em suas dimensões formalistas. Esse problema foi indicado por Freud (1914/1992), embora tenha recaído sobre Ferenczi o predicado da ousadia em relação às inovações técnicas para oferecer um dispositivo clínico sintônico aos chamados "casos difíceis" que batiam à sua porta. Esse psicanalista tomou para si a tentativa de vencer as resistências, verdadeiros "pontos mortos" (FERENCZI, 1921/1993, p.111) que tornavam inoperantes a interpretação e a atitude de distanciamento do analista. Em última instância, a clínica tal como concebida na perspectiva ferencziana buscava tratar as resistências evidenciadas pela compulsão à repetição, ou seja, nas dimensões dinâmica e econômica que não teriam sido suficientemente contempladas do ponto de vista clínico no pensamento freudiano.

Suas peculiaridades técnicas ganharam corpo por ocasião da técnica ativa, cujo objetivo era redistribuir a energia psíquica mediante frustrações sugeridas pelo analista, ou seja, elaborar as resistências advindas de experiências traumáticas impossibilitadas de serem rememoradas e, portanto, interpretadas. Entretanto, Ferenczi (1926/1993) esbarrou no fato de a técnica ativa acirrar as resistências, concorrendo para a exigência de reservá-la às análises que já teriam avançado suficientemente e necessitariam apenas da dissolução da transferência.

Tem lugar então o princípio de relaxamento e neocatarse, que consiste em instituir o laissez-faire ao lado do princípio de frustração (FERENCZI, 1930/2003). Trata-se de uma técnica que prima pela elasticidade da clínica, aventada no vai- 
vém das resistências tanto do analisando quanto do analista. Seja do lado de um ou de outro, é como se Ferenczi (1985/2003) propusesse uma clínica orientada pelo que chamamos de termômetro das resistências, o qual, conforme a temperatura, pode determinar que o elástico estique mais para um ou outro lado na tarefa de redistribuição das intensidades recalcitrantes ao dispositivo analítico. Assim, o imperativo de elucidação das resistências para superá-las deve ser matizado em um manejo clínico que as inclui como fio norteador do cuidado que busca oferecer ao paciente.

Aliás, é importante indicar que não se trata apenas da resistência a serviço de resguardar a consciência do desconfortável embate com o recalcado, as resistências da esfera do eu, mas também "de transferência dos afetos e de resistência afetiva" (FERENCZI, 1930/2003, p.55). O analista deve vibrar conforme o diapasão do analisando, como um elástico que cede às tendências do último, em uma atitude de benevolência necessária para que os afetos de desprazer sejam trabalhados. É importante que o elástico também tensione, todavia, no sentido do analista, que não deve abandonar suas próprias opiniões, como a figura “neutra” presente no referencial freudiano permitia supor.

Desse modo, a clínica ferencziana busca uma técnica capaz de contemplar as resistências que ultrapassam a esfera do eu, descritas por Freud (1926[1925]/1992) apenas no quadro de sua segunda tópica. Estas estão associadas ao isso, representadas pela compulsão à repetição e pela adesividade da libido, e ao supereu, nesse caso expressa pela reação terapêutica negativa. Trata-se de tipos de resistência que preconizam um manejo clínico que vise à dimensão quantitativa da análise, norteadas pela exigência das modificações dinâmica e econômica do psiquismo. Em suma, o que está em questão é a elaboração em sua vertente quantitativa, assunto debatido a seguir em sua articulação com o trauma.

\section{O TRAUMA COMO DESAFIO À ELABORAÇÃO}

Assim como feito em relação à resistência, é preciso revisitar o conceito de elaboração, cujo aspecto que extrapola o imperativo de acessar o recalcado impôsse como desafio para a clínica desde a leitura da transferência também como resistência. Do alemão Durcharbeitung, ${ }^{1}$ o termo foi traduzido por perlaboration em francês (FREUD, 1914/2005), neologismo capaz de indicar que algo escapa à elaboração enquanto processo cognitivo pelo qual a interpretação é assimilada graças a uma modificação tópica (LE GUEN, 2008). Neste artigo, optar-se-á por

\footnotetext{
${ }^{1}$ Em alemão, die Durcharbeitung é um substantivo que significa estudo minucioso, decorrente do verbo durcharbeiten que, por sua vez, pode ser traduzido por 'trabalhar ininterruptamente'.
} 
conservar o termo 'elaboração’, muito embora se espere enaltecer a dimensão quantitativa do trabalho com as resistências.

Segundo Roussillon (2008), há diferentes registros de funcionamento da elaboração na obra freudiana: o primeiro refere-se ao trabalho com as resistências do eu — o qual caracterizamos como predominantemente cognitivo enquanto o segundo destina-se à elaboração das resistências associadas ao isso e ao supereu, alvo primordial da clínica ferencziana. O primeiro registro aponta para uma elaboração que, conforme Aisenstein (2000), podemos compreender como eminentemente interpretativa, ou seja, propiciada graças ao método da interpretação; ao passo que o segundo busca trabalhar a perspectiva quantitativa da clínica, na qual a técnica interpretativa revela-se insuficiente.

É oportuno esclarecer que Ferenczi dedicou-se às reformulações técnicas também por conta de uma questão diagnóstica, quer dizer, para dar conta dos "casos difíceis" dos quais se ocupara e que, conforme a sua leitura, seriam fruto de uma marcante experiência traumática. A ênfase ao trauma já figurava na hipótese etiológica de Freud acerca dos sintomas neuróticos, mas Ferenczi vai além para construir uma verdadeira teoria da traumatogênese.

Ferenczi (1932/2003) elabora sua teoria a partir de uma cena traumática em que um adulto abusa sexualmente de uma criança, a qual, por sua vez, procura um segundo adulto a quem possa relatar a experiência. Antes de tudo, é fundamental explicitar que o adulto (autor do abuso) e a criança possuem diferentes "linguagens", o primeiro respondendo pela linguagem da paixão, ao passo que a criança é provida da linguagem da ternura. Trata-se de um apontamento deveras importante, pois a criança seduz o adulto abusador, mas essa sedução está fora da alçada do jogo que perpassa a relação entre adultos. Ao contrário, a criança seduz o adulto orientada pela ternura de caráter lúdico, ao que o adulto responde nos parâmetros da paixão.

Na impossibilidade de compreender o ocorrido devido ao desencontro de linguagens, “confusão de línguas” em termos ferenczianos (FERENCZI, 1932/2003), a criança busca o suporte de outro adulto com vistas, em última instância, a elaborar a experiência que ultrapassou sua capacidade de compreensão. É como se a criança buscasse nesse segundo adulto um intérprete para o sentimento de culpa que o adulto abusador lhe transmitiu, sentimento que a primeira ainda se revela incapaz de alcançar (PINHEIRO, 1996).

Por fim, para que a cena adquira o predicado de traumática, o adulto investido como intérprete deve falhar em sua função, desacreditando a fala sobre a experiência vivida pela criança. Tem lugar então o desmentido, a desautorização por parte de um terceiro da verdade trazida pela criança abusada. Assim sendo, é o desmentido - e não propriamente o abuso - que impede que a criança introjete a experiência vivida. Cabe uma pequena digressão para indicar que, 
segundo Ferenczi (1909/1988), o processo de introjeção é constitutivo do psiquismo, por meio do qual os objetos são introduzidos no eu. Trata-se da forma pela qual a esfera do eu é ampliada, contrapondo-se, portanto, à incorporação, processo instantâneo disparado a partir da experiência traumática (ABRAHAM \& TOROK, 1995).

Na impossibilidade de introjeção da experiência, resta à criança a identificação com o adulto abusador, incorporando-o. A criança, afirma Ferenczi (1932/2003), é forçada a amadurecer precocemente, em um processo de amadurecimento denominado progressão traumática, cuidando "de si e dos outros, ao preço de renunciar ao seu eu infantil e terno” (LEJARRAGA, 2008, p.122). É como se a criança buscasse salvaguardar o adulto abusador e seu próprio psiquismo graças a uma divisão que ocorre na esfera do eu, o mecanismo da autoclivagem narcísica (FERENCZI, 1931/2003). Com essa modificação, uma parte do eu incorpora o adulto abusador, propiciando que o restante do eu desconheça a experiência traumática e se mantenha à parte do ocorrido. Trata-se de uma estratégia para que o eu possa, nem que seja parcialmente, sobreviver ao trauma, como se o mesmo não tivesse se dado.

A questão é que embora a autoclivagem busque anular as vicissitudes nocivas do trauma por intermédio da incorporação, ainda assim não se mostra suficiente para silenciar tais destinos, mesmo porque, conforme indicado pelo próprio Freud, o eu apresenta uma irrevogável tendência à integração, tendência esta que é contrariada pela clivagem (VERZTMAN, 2002). A incorporação deixa então seus rastros, compreendidos por Abraham e Torok (1995) nos termos de uma cripta, como um corpo estranho que não se integra ao restante do eu. Na impossibilidade de ser introjetada, a cripta não é inserida em uma cadeia representacional, revelando-se, por isso, incapaz de aceder à consciência pela via interpretativa.

Temos com Roussillon (1999) que as partes do eu cindidas pela autoclivagem narcísica podem ser assim descritas: uma delas se exprime como um encadeamento de representações, enquanto a parte restante e encriptada indica o que se furta à representação. Assim sendo, a teoria ferencziana permite supor a existência de modos de funcionamento diferentes em decorrência do trauma, sendo que um se enquadraria nos moldes propostos por Freud para o tratamento das neuroses clássicas, enquanto o segundo apresentar-se-ia especialmente recalcitrante ao dispositivo da interpretação que lançou luz ao método psicanalítico na modernidade que lhe serviu de berço.

Os ensinamentos advindos da teoria ferencziana da traumatogênese mostramse, dessa maneira, sintônicos às modalidades de padecimento psíquico que supomos serem amplamente encontradas na cultura contemporânea, marcada pela suscetibilidade ao trauma. O manejo clínico deve levar em consideração a 
estabilidade da clivagem, cujas vicissitudes nem sempre se dão a ver em comparação com as formações sintomáticas decorrentes do recalque; a progressão traumática, uma vez que também o tratamento pode se tornar traumático caso o sujeito não desfrute da benevolência necessária por parte do analista para nele confiar os seus afetos e, por fim, a dimensão sensível da elaboração (KUPERMANN, 2010), que está para além do trabalho interpretativo destinado às resistências do eu.

O que fica em evidência é o que denominamos 'dimensão sensória da linguagem’ (HERZOG, 2010), a qual extrapola a dimensão formalista da última, evidenciada na construção metafórica e outras formas de representação clássicas. Entendemos que é preciso estar atento às manifestações linguageiras que escapam à possibilidade de apalavrar o mal-estar, fio norteador da clínica na perspectiva freudiana, assim como primar pela criação de formas de manejo clínico que não sejam exclusivamente pautadas pelo imperativo de representar, em sua acepção tradicional, o trauma (HERZOG, 2011). Assim, busca-se um antídoto frente à progressão traumática, propiciando ao sujeito um ambiente acolhedor para que tenha lugar a elaboração do trauma, trabalho que não pode prescindir, no entanto, de resistências.

Nesse sentido, cabe indagar qual seria o lugar do analista perante uma dimensão da linguagem que ultrapassa a construção metafórica que aprendemos a entender como manifestações de resistência por parte do analisando. Qual é, afinal de contas, a convocação que a linguagem das resistências faz ao analista? Para tentar esboçar uma resposta, ainda que preliminar, cumpre detalhar o que estamos chamando de dimensão sensória da linguagem em comparação com sua acepção clássica.

\section{O ANALISTA COMO TRADUTOR DA LINGUAGEM DAS RESISTÊNCIAS}

Afirmamos, desde a introdução, a convocação na experiência traumática de uma dimensão da linguagem que extrapola aquela perspectiva formalista, cuja ênfase recai no modelo da construção metafórica. De acordo com a teoria ferencziana sobre a traumatogênese, apresentada na seção precedente, é possível associar essa perspectiva da linguagem aos desdobramentos da cripta, que permanece como um corpo estranho às cadeias de representações inscritas psiquicamente e, portanto, recalcitrantes ao dispositivo da interpretação.

Mas, afinal de contas, de que dimensão da linguagem se trata? Para esboçar suas características, faz-se profícuo recorrer a autores que se dedicaram a uma abordagem que escapa à corrente estruturalista francesa, tributária do pensamento do linguista Ferdinand de Saussure e amplamente em voga após a Segunda Guerra Mundial. No movimento psicanalítico, o estruturalismo francês teve eco 
graças às formulações de Jacques Lacan, expressivamente difundidas entre os psicanalistas brasileiros.

Em linhas gerais, a concepção de linguagem na perspectiva estruturalista enaltece a arbitrariedade do signo. Para comentar a assertiva, convém seguir as indicações de Saussure, para quem "o signo é o fato central da linguagem" (CULLER, 1979, p.14) constituído por significante, uma forma, e significado, uma ideia. A relação entre ambos é, segundo o linguista em pauta, absolutamente arbitrária, ou seja, não há nenhuma ligação apriorística ou necessária capaz de explicar a unidade linguística na qual consiste o signo.

A questão da arbitrariedade do signo em Saussure não constitui o foco do presente trabalho e está muito longe de ser esgotada em alguns breves comentários. Ao contrário, foi alvo de acirradas discussões no campo da Linguística, entabulada por expoentes comentadores, dos quais constitui um exemplo o teórico Benveniste. ${ }^{2}$ Nos limites estabelecidos para este artigo, faz-se premente indicar que a leitura psicanalítica sobre a linguagem destacada por Lacan, apoiada na teoria saussureana, não constitui ponto consensual, embora, de fato, seja amplamente utilizada no campo.

Além da concepção embasada pelo estruturalismo francês, é possível ainda mencionar aquela presente nas afirmações de Ferenczi. Conforme o último, a motivação preponderante para a construção de um símbolo é de natureza afetiva e não intelectual. A criança estabelece relações entre coisas diferentes com base em uma semelhança aparentemente insignificante, aos olhos dos adultos, e "desloca facilmente seus afetos de uma para a outra, atribuindo-lhes o mesmo nome” (FERENCZI, 1913/2003, p.105). Trata-se do estabelecimento de relações de semelhanças entre o corpo da criança e o mundo que a circunda, falando a favor de uma visada a respeito do simbólico que não coincide com aquela popularizada por Lacan. Como esclarece Gondar (2010), a “espinha dorsal dos processos de simbolização não reside na linguagem ou na capacidade de representar, mas na possibilidade de estabelecer semelhanças no plano da sensorialidade” (p.126).

A capacidade de representar — e de construir metáforas — é um dos predicados da linguagem e das possibilidades de simbolizar, mas não a única. Nessa perspectiva, as palavras despontam com a possibilidade de imitar as coisas. Para ilustrar a proposta, convém retomar um exemplo empregado por Ferenczi. É possível observar o fato de as crianças associarem as figuras do pênis e da árvore, uma analogia estabelecida entre uma parte do corpo e um objeto pertencente ao mundo que as cerca. Segundo Ferenczi (1913/2003), a analogia serve de suporte à construção de um símbolo, de maneira que quando a educação cultural

\footnotetext{
2 Émile Benveniste foi um grande linguista francês que se empenhou na crítica ao caráter arbitrário do signo. Para mais informações sobre a discussão, sugerimos Benveniste (1989) e os comentários tecidos por Diniz (2010).
} 
preconiza "o recalcamento de um dos termos da analogia (o mais importante) é que o outro termo (o mais insignificante na origem) adquire um suplemento de importância afetiva e converte-se num símbolo do termo recalcado" (p.107).

Os termos mais "importantes", ou seja, investidos afetivamente "na origem", perdem sua intensidade devido ao recalcamento, como se a analogia mais imediata e direta estabelecida pela criança entre as partes do seu corpo e o mundo fosse enfraquecida pelas restrições da civilização e pelo processo de unificação das pulsões parciais apoiadas nas zonas erógenas descritas por Freud (1905/1988). Ainda que atenuadas, as semelhanças não se perdem, pois as palavras imitam as coisas, atestando que "um halo da coisa estaria presente na palavra" (GONDAR, 2010, p.127), isto é, há algo da coisa que se presentifica na última. É como se houvesse um atrito das letras com o real, conforme sugere o escritor Reinaldo Moraes (2011) ao tratar o seu trabalho como "literatritura" (p.211). Esse atrito das palavras com o real seria, inclusive, minimizado com a construção metafórica, na medida em que diminuiria a dimensão intensiva da qual, de acordo com Ferenczi, são providas as palavras.

Essa leitura é de grande contribuição para a compreensão das vivências traumáticas, uma vez que nestas "a distância entre as palavras e as coisas diminui, o que faz com que os sujeitos (...) tendam a 'sentir' as palavras, usando-as literalmente" (GONDAR, 2010, p.130). O choque traumático é, assim, uma ocorrência capaz de resgatar a dimensão intensiva das palavras, privilegiando a literalidade em detrimento de construções como as metáforas. De maneira análoga, palavras carregadas de afeto e encriptadas tornam o discurso absolutamente recalcitrante ao dispositivo clássico da psicanálise, a interpretação, tido como modalidade de intervenção diante dos casos de histeria com os quais Freud se deparou no início de seu percurso como clínico.

Assim, as vicissitudes da experiência traumática evidenciam o que estamos chamando de linguagem das resistências, caracterizada por palavras intensas e apartadas das cadeias de representações. Convém problematizar a convocação que fazem ao analista, tendo em vista que as mesmas podem ser compreendidas como uma mera manifestação de resistência que deve ser superada para que a experiência analítica prossiga "satisfatoriamente", embora também apontem para a linguagem que se mostra possível, tendo em vista os efeitos do choque traumático e da subjetividade clivada que lhe é correlata.

Já que a técnica interpretativa mostra-se inoperante em tais circunstâncias, como compreender o trabalho de elaboração em sua dimensão quantitativa? Qual seria o lugar do analista, posto que a via da interpretação não se revela profícua nesse cenário? Com efeito, há que se pensar em outra função para o analista para além de intérprete do recalcado e da orientação de uma modificação tópica como eixo principal do trabalho de elaboração. Gondar (2010) deixa 
indicado que a intervenção até poderia ser concebida em termos de interpretação, desde que esta não se restringisse ao exercício de suspeita que busca revelar o recalcado, cujo retorno teria ficado subjacente à fala consciente. Ao contrário, a interpretação destinada à linguagem das resistências deveria ser utilizada no intuito de "restaurar uma ligação" (GONDAR, 2010, p.131), ligação esta perdida por conta da cisão subjetiva atrelada à clivagem. No lugar da suspeita, caberia ao analista uma postura de confiança nas palavras enunciadas pelo analisando, ainda que predominantemente marcadas pelo recurso da literalidade. A possibilidade de compreensão da técnica interpretativa fora da alçada do exercício da suspeita nos fez retomar os apontamentos de Walter Benjamin no tocante às fissuras inerentes à narrativa. Sendo assim, entendemos que sua concepção de tradução pode ser produtiva, uma vez que o termo interpretação está marcadamente associado ao trabalho de investigação do recalcado nas produções do campo psicanalítico.

A discussão empreendida por Benjamin sobre a tarefa do tradutor se insere em uma perspectiva mais ampla de suas teses sobre a linguagem humana em cuja tradição é possível inserir, a posteriori, também Ferenczi, posto que ambos entendem que a aquisição da linguagem se dá por intermédio da imitação. Para Benjamin, a linguagem humana apresenta a particularidade de nomear as coisas, o que seria, por isso, “a essência linguística do homem” (BENJAMIN, 1916/2000, p.146). No entanto, cumpre esclarecer que o homem se comunica nas palavras que atribui às coisas e não através das palavras. Trata-se de uma indicação importante, pois as teses benjaminianas problematizam a "concepção burguesa de linguagem” (p.147), segundo a qual a palavra seria o meio da comunicação, o objeto seria a coisa e o homem seria o receptor a quem se destina todo o processo.

Assim, temos que "o nome é este pelo qual nada se comunica mais, e no qual a linguagem se comunica, ela própria, de forma absoluta” (BENJAMIN, 1916/2000, p.147), de modo que há sempre um resto incomunicável, indizível, que entrava a transmissão absoluta do emissor ao receptor. A própria ideia de comunicação - que se dá por intermédio das palavras e visa um receptor — está em xeque, se for entendida como plenamente comunicável. Não há um conteúdo transmissível da linguagem, daí a afirmação de que a linguagem se comunica ela própria, por alusão ao que Benjamin chama de "língua pura". 3

Do mesmo modo, Benjamin (1923/2000) ressalta que o tradutor não deve se preocupar com um sentido a ser transmitido, mas com a forma, seu principal objeto. Dito de outra maneira, a tarefa do tradutor não busca a comunicação de

\footnotetext{
${ }^{3}$ Benjamin entende por língua pura aquela que todas as demais querem dizer (sem êxito) e para a qual todas convergiriam. Trata-se de uma alusão à língua adâmica que precedeu a Torre de Babel, destruída devido ao castigo divino que se abateu sobre os homens. O tradutor seria capaz de dar forma à língua pura, tendo em vista sua tarefa de juntar as línguas com as quais trabalha e de instituir a complementaridade entre estas.
} 
um conteúdo de uma língua à outra, mas a complementaridade de línguas. Isso quer dizer que uma tradução não deve escamotear as diferenças entre as línguas em questão, pois a verdadeira tradução "não esconde o original, não o eclipsa" (BENJAMIN, 1923/2000, p.257).

A leitura de Benjamin nos fez supor, ainda que de maneira preliminar para os limites deste artigo, que o analista não seria propriamente um intérprete da chamada linguagem das resistências — posto que a interpretação estaria fortemente vinculada à atitude de suspeita — , mas um legítimo tradutor, se a tarefa deste for depreendida da teoria benjaminiana. Isso porque a convocação feita ao analista pela experiência de choque traumático aponta para a exigência de confiança, justamente o que falta, segundo a teoria ferencziana da traumatogênese, à criança quando o adulto ao qual recorre para elaborar o ocorrido desmente a sua palavra.

A experiência analítica poderia, assim, funcionar como espaço em que diferentes linguagens poderiam ser expressas, sem que nenhuma delas fosse necessariamente subsumida por uma interpretação por parte do analista. Por oposição à confusão de línguas da qual fala Ferenczi (1932/2003) para ilustrar a cena do trauma, teria lugar a complementaridade de línguas, da qual faz parte a linguagem das resistências, em suas múltiplas versões, seja do lado do analisando ou até mesmo do analista.

Recebido em 17/5/2012. Aprovado em 2/8/2012.

\section{REFERÊNCIAS}

ABRAHAM, N. \& TOROK, M. (1995) 'Luto ou melancolia, introjetarincorporar". In: \& A casca e o núcleo. Rio de Janeiro:

Escuta.

AISENSTEIN, M. (2000) Élaboration, perlaboration, cicatrisation. Revue Française de Psychanalyse, vol. 64 (4), Paris: PUF.

BENJAMIN, W. (2000) Walter Benjamin. Fuvres I. Paris: Gallimard.

(1916) “Sur le langage en général et sur le langage humain”, v.I, p.142165.

(1923) La tâche du traducteur, v.I, p.244-262.

(1932) “Experiènce et pauvreté', v.I, p.364-372.

(1936) Le conteur. Réflexions sur l'ouvre de Nicolas Leskov, v.III, p.114-151.

BENVENISTE, E. (1989) “Natureza do signo linguístico”. In: Problemas de linguística geral, v. I. Campinas: Pontes.

BIRMAN, J. (2003) “Reviravoltas na soberania”. In: Arquivos do mal-estar e da resistência. Rio de Janeiro: Civilização Brasileira. 
BOKANOWSKI, T. (2002) Traumatisme, traumatique, trauma. Revue Française de Psychanalyse, v.66 (3), Paris: PUF.

CULLER, J. (1979) As ideias de Saussure. São Paulo: Cultrix.

DINIZ, L.R.A. (2010) A unidade linguística e o sistema e a teoria saussureana: uma relação indissociável. Cadernos de Estudos Linguísticos, v.52, n.1, p.65-73.

FERENCZI, S. (1909/1988) “Transferência e introjeção”. In: BIRMAN, J. (Org.) Sándor Ferenczi: Escritos psicanalíticos 1909-1933. Rio de Janeiro: Taurus.

(2003) Obras completas: Psicanálise. São Paulo: Martins Fontes, p.105-108.

(1913) “Ontogênese dos símbolos”, v.II, p.105-108.

(1921/1993) “Prolongamentos da 'técnica ativa” em psicanálise”, v.III, p.109-125

(1926/1993) “Contra-indicações da técnica ativa”, v.III, p.365-375.

(1928/2003) "Elasticidade da técnica psicanalítica”, v.IV, p.25-36.

(1930/2003) “Princípio de relaxamento e neocatarse”, v.IV, p.5368.

(1931/2003) “Análise de crianças com adultos”, v.IV, p.69-83.

(1932/2003) "Confusão de língua entre os adultos e a criança”, v.IV, p. $95-106$.

(1895/2003) “Notas e fragmentos”, v.IV, p.235-284.

FREUD, S. (1988) Obras completas. Buenos Aires: Amorrortu.

(19058) “Tres ensayos de teoria sexual”, v.VII, p.31-69.

(1914/1992) "Recordar, repetir y reelaborar”, v.XII, p.35-38.

(1918[1914]/1990) "De la historia de una neurosis infantil", v.XVII, p.1-34.

(1920/1992) “Mas allá del principio de pracer”, v.XVIII, p.1-17.

(1925[1924]/1990) “Las resistencias contra el psicoanálisis”, v.XIX, p.54-57.

(1926[1925]/1992) “Inhibición, síntoma y angustia”, v.XX, p.2045.

(1914/2005) “Remémoration, répétition et perlaboration”. In: Euvres Complètes. Psychanalyse, v. XII. Paris: PUF.

GONDAR, J. (2010) As coisas nas palavras. Ferenczi e a linguagem. Cadernos de Psicanálise do CPRJ, ano 32, v.23, p.123-132.

HERZOG, R. (2006) “O contemporâneo do sintoma”. In: FIGUEIREDO, A.C. (Org.) Corpo, sintoma e psicose: leituras do contemporâneo. Rio de Janeiro: Contra Capa.

(2010) “A dimensão afetiva da linguagem na experiência psicanalítica”. In: OLIVEIRA, C. (Org.) Filosofia, psicanálise e sociedade. Rio de Janeiro: Beco do Azougue.

(2011) "Os limites da representação psíquica”. In: GARCIA, C.A. \& CARDOSO, M.R. (Orgs.) Limites da clínica, clínica dos limites. Rio de Janeiro: Cia de Freud/FAPERJ.

KUPERMANN, D. (2010) A via sensível da elaboração. Caminhos da clínica psicanalítica. Cadernos de Psicanálise - CPRJ, Rio de Janeiro, ano 32, n.23, p.31-45. 
LEJARRAGA, A.L. (2008) Clínica do trauma em Ferenczi e Winnicott. Natureza Humana, v.10, n 2, p.115-147.

MEYER, C. (Sous la direction de) (2005) Le livre noir de la psychanalyse. Vivre, penser et aller mieux sans Freud. Paris: Les Arènes.

MORAES, Reinaldo. (2011) “Tanto faz”. In: Tanto Faz \& Abacaxi. São Paulo: Companhia das Letras.

PINHEIRO, T. (1996) “Trauma e melancolia”. In: KATZ, C.S. (Org.). Férenczi: história, teoria, técnica. São Paulo: Ed. 34.

ROUSSILLON, R. (1999) Agonie, clivage et symbolisation. Paris: PUF.

. (2008) La perlaboration et ses modèles. Revue Française de Psychanalyse, v.72, n.3, p.855-867.

VERZTMAN, J. (2002) O observador do mundo: a noção de clivagem em Ferenczi. Ágora, v.V, n.1, p.59-78.

Fernanda Canavêz

fernandacanavez@gmail.com

Regina Herzog

rherzog@globo.com 